\title{
DEVELOPING A QUANTITATIVE INDEX OF INTEGRITY AS A COMPREHENSIVE MEASURE IN ECOLOGICAL CHANGE ANALYSIS
}

\author{
RASOULI, S. ${ }^{1}{ }^{*}-$ MAKHDOUM FARKHONDEH, M. $^{2}-$ SUFFLING, R. ${ }^{3}-$ JAFARI, H. R. $^{1}$ \\ ${ }^{1}$ Faculty of Environment, University of Tehran, 25, Ghods Street, P.O. Box: $14155-$ \\ 6135, Tehran, Iran \\ (phone: +98-21-6111-3165, fax: +98-21-6640-7719) \\ ${ }^{2}$ Faculty of Natural Resources, University of Tehran, P.O. Box 4111, Karaj, Iran \\ (phone: +98-21-8897-2473, fax: +98-21-6697-1247) \\ ${ }^{3}$ Faculty of Environment, University of Waterloo, 200 University Avenue West, Waterloo, ON \\ N2L 3G1, Canada \\ (phone: +1-519-8884-567, fax: +1-519-7252-827) \\ *Corresponding author \\ e-mail: Sadie.rasouli@gmail.com \\ (Received $14^{\text {th }}$ Aug 2014; accepted $1^{\text {st }}$ Dec 2014)
}

\begin{abstract}
Ecological Integrity is one of the main scientific measures in the comprehensive assessment of ecosystems. The purpose of this study was to: (a) find a way to depict the disturbance gradient of our case study in northern Iran (b) develop an index of biotic integrity; (c) finally provide a baseline for assessing ecological integrity. Analytical metrics of spatial composition and configuration were applied to identify the disturbance gradient. Estimating of these metrics helped to define three levels of disturbance using the Ward's method of clustering analysis. A quantitative index of integrity was constructed, using three types of bird guilds including structural, functional and compositional .Results showed the range of integrity index at Miankaleh Peninsula was a value from 26 to 68. Statistical analysis including One-Way ANOVA and Pearson Correlation and paired sample t-test were conducted to investigate the validity and reliability of the Index. Findings of this research showed that biotic integrity in parts of the Miankaleh Peninsula was far from its intact condition. Developed index of biological integrity in this research can help to assess effects of the disturbance factors on the natural ecosystem of Miankaleh to prioritize the best management actions for restoring of this ecosystem.
\end{abstract}

Keywords: statistical examination, disturbance gradient, intact condition

\section{Introduction}

The concept of integrity has many applications and has become a main scientific measure in the comprehensive assessment and monitoring of ecological systems. Karr and Dudley (1981) defined ecological integrity as " the capability of supporting and maintaining a balanced, integrated, adaptive community of organisms having a species composition, diversity, and functional organization comparable to that of natural habitat of the region". This definition has been adopted by many authors including Andreason (2001), Bedoya (2009), Diffendorfer (2007) and Glennon (2005).

Indices of biotic integrity ideally compare a present ecological condition to a pristine reference point (Miller, 2006). Several studies have developed indices of integrity for aquatic and arid ecosystems (Angermeier and Davideanu, 2004; Borja et al., 2009; Karr and Chu, 1999; Rothrock et al., 2003; Solimini et al., 2008). Related indices have been developed for shrub-lands and steppe areas (Karr and Chu,1999; Kimberling et al., 
2001), rangelands and grasslands (Borges et al., 2000; Bradford et al., 1998; Browder et al., 2002; Taft et al., 2006), and forests (Brooks et al., 1998;Cardoso et al., 2007; Glennon and Porter, 2005; Majer and Beeston, 1996 and O'Connell et al., 2000).

Unfortunately, in many regions of Earth, the lack of historical ecological information is a strong impediment to adoption of ecological integrity as a management principle. Due to scarcity of historical data, various biological variables have been used in assessing the integrity of arid ecosystems. (Bradford et al., 1998; Brooks et al., 1998 and O'Connell et al., 2000). Selecting an appropriate biological index is thus extremely important in the analysis of integrity that can be evaluated from different perspectives. Considering habitat as the perspective of integrity (Woodley, 1993), one should select indicator species that are dependent on the habitat structure in relation to the disturbance factors in the region under study. Since it is not possible in theory and in practice to find two species with the same ecological niche, selecting a single species to represent biotic integrity can have deficiencies. (Cairns and Van der Shalie, 1980; Carignan, 2001; Franklin, 1993; Lambeck, 1997; Rapport, 1990 and Walker, 1995). Thus many scholars have stressed considering higher organizational levels such as ecosystem landscape (Dyer and Holland, 1991; Franklin, 1993; Gosselink et al., 1990; Hobbs, 1994; Noss, 1983; Noss, 1987).

Functional groups are associations of organisms that have similar competition interactions, habitat requirements and evolutional history (Andersen, 1995). When a disturbance factor causes a considerable change in ecosystem structure, functional groups provide an appropriate framework for assessing the response of the community to that disturbance factor (Hoffman and Anderson, 2003).

Generally birds are appropriate for constructing indices for assessing integrity (Blair, 1996; Cody, 1981; Croonquist and Brooks, 1991; Dearborn et al., 2001; Donovan et al., 1995 and Freemark and Collins, 1992). Birds' state in an ecosystem can explain the structural, functional and compositional structure of the ecological system (O'Connell, 2000).

These three adequately represent the integrity condition of an ecological system (Carignan and Villard, 2001; Karr, 1981; Noss, 1987 and Muller, 2005). Bird guilds have a significant relation with disturbance factors and can be an effective index of habitat disturbance (Blair, 1996; Cody, 1981; Croonquist and Brooks, 1991; Dearborn et al., 2001 and Donovan et al., 1995).

In addition to various studies above on developing an Index of Biotic Integrity (IBI), there are specific reasons for us to continue this work in the Miankaleh peninsula of Iran. The purpose of this study was to: (a)depicting the disturbance gradient in the study area(b) develop an appropriate quantitative index of integrity (c) assess changes happen to the developed index of integrity during a gradient of disturbance, (d) finally assessing ecological integrity of Miankaleh peninsula.

\section{Materials and Methods}

The Miankaleh peninsula (12228 ha, 5302 - 5325 longitude and 36 55-36 48 latitude), portion of the Miankaleh Biosphere Reserve in the south-east extremity of the Caspian Sea in North of Iran is the study area. The Peninsula is a relatively flat, elongate sand dune separating Gorgan Bay from the Caspian Sea. The mean annual precipitation is $600-700 \mathrm{~mm}$. Precipitation quickly penetrates the soils so that there are no watercourses in the study area. It has humid and mild climate. The peninsula's 
vegetation is composed of three major formations; shrub, heath, and grassland. The shrub Formation is dominated by pomegranate (Punica granatum); the main species of heaths is Rubus persicus, Juncus spp. and several annual grasses cover the area between shrubs, especially in spring and early autumn (DOE, 2002).

The importance of Miankaleh region derives from the wintering of many rare species of migrant birds and the breeding of native and resident bird species in summer.

A variety of natural and anthropogenic factors are forcing Miankaleh in ways that in some parts have moved it far from its pristine integrity. Overgrazing in shrub-lands is the major disturbance factor that has decreased shrubs' density in the study area (DOE, 2007).

With the goal of assessing ecological integrity, one may determine the relationships between current biological state of integrity indices and the degree of disturbance in the study area. Considering over-grazing as the main disturbance factor in Miankaleh and also the importance of shrub-lands from habitat point of view in this area, the changes in this vegetation cover were considered as the key attribute for developing the gradient of disturbance in the study area. To determine disturbance gradients, we required sampling sites ranging from intact natural environments to disturbed ones. Determining the natural condition of the shrub-lands, we constructed land cover maps that could show the past vegetation, using digital image classification. The best available data were Landsat TM5 with 30-meter resolution, with the earliest proper images from 1985. Moreover, land cover maps of current condition of the ecosystem were constructed using Images of Landsat TM5 from 2010. A supervised classification was conducted in ENVI 3.00 program using maximum likelihood estimation. Different classes of land cover maps were defined using classes in the master land-use map prepared by Ministry of Forest and Natural Resources of Iran (DOE, 1988). Both of these land cover maps were ground truthed using land use map of 1988 and data of ground truth sampling of 2010, respectively. Two land cover maps of 1985 and 2010 were created with an overall accuracy of $80 \%$ and $85.5 \%$ respectively. Table 1 shows different classes of land cover maps of 1985 and 2010.

Table 1. Different classes of Land cover Maps of 1985 and 2010

\begin{tabular}{|c|c|}
\hline Land Cover classes of 1985 & Land cover classes of 2010 \\
\hline $\begin{array}{c}\text { Dense shrub-lands (Density of } \\
\text { shrubs more than 50\%) }\end{array}$ & $\begin{array}{c}\text { Dense shrub-lands (Density of shrubs } \\
\text { more than 50\%) }\end{array}$ \\
\hline Rangeland & $\begin{array}{c}\text { Low Dense shrub-lands (Density of } \\
\text { trees less than 50\%) }\end{array}$ \\
\hline Wetland Vegetation & Rangeland \\
\hline Agricultural land & Wetland Vegetation \\
\hline Bare Area & Agricultural land \\
\hline Water & Bare Area \\
\hline--- & Water \\
\hline
\end{tabular}


Intersecting the land cover maps of 1985 and 2010 in ArcGIS and employing field reconnaissance, sampling sites were chosen through the study area.

Regarding density; the amount of tree material per unit area; of the shrub coverage as a measure of change monitoring, intersecting of the two land cover maps showed the amount of change in dense shrubs over time. Bearing in mind the goal of this research, the focus was directed to changes in areas of dense shrubs. The areas in which there have been dense shrubs at both times are regarded as showing intact or normal conditions. Parts of mentioned areas have been zoned as core areas in Miankaleh biosphere reserve (DOE, 2007), and this also supports the contention that these areas almost are in the intact condition. Looking at the changed areas in intersected land cover maps, some parts of dense shrubs with a density of more than $50 \%$ that have changed to shrub-lands with a density of less than $50 \%$ and the parts that changed to bare areas were considered, respectively, as second and third categories that have changed from their intact conditions.

Eight1000-meters transects from north to south were laid randomly along the peninsula considering a category of high density shrub-land, moderate density shrubland and bare area.

Diverse variables along each transect should be compared in order to distinguish a significant level of disturbance gradients. Since the available ecological data of the current condition of the ecosystem are not adequate to discern ecological state in area surrounding each transect, there was a need of indicators to distinguish and quantify disturbance degree in the areas surrounding each transect. For this, in Arc Map a polygon of 2000-meter diameter was depicted around each transect.

Hence, the landscape metrics of spatial composition and configuration inside each polygon were applied as variables in the recognition and analysis of disturbance gradient. Table 2 shows the list of landscape metrics used for estimating the disturbance gradient.

Table 2. Landscape Metrics used for Estimating Disturbance Gradient

\begin{tabular}{|l|l|}
\hline \multicolumn{1}{|c|}{ Metric } & \multicolumn{1}{c|}{ Application } \\
\hline Class Area (CA) & $\begin{array}{l}\text { Characterizing how much of the landscape is comprised of } \\
\text { a particular patch type }\end{array}$ \\
\hline Percentage of Landscape(PLAND) & Measuring Patch Area Distribution using Mean Area \\
\hline Aggregation Index (AI) & $\begin{array}{l}\text { Presents the Percentage of relative aggregation of each } \\
\text { class }\end{array}$ \\
\hline Percentage of Like & Measures the degree of aggregation of the patch type \\
\hline SPLIT & Shows level of patchiness in a class \\
\hline COHESION & A measure of Connectivity of different patches of a class \\
\hline
\end{tabular}

The two land cover maps served as the input for quantifying the landscape structure inside the borders of polygons based on the following steps:

- Generating grid files from land cover maps and exporting in to FRAGSTAT program 
- Parameterization of the selected metrics in FRAGSTAT program(UMass)

- Estimation of landscape metrics inside the polygons by running the FRAGSTAT program

Regarding the research goal, among the great number of metrics related to different classes in each depicted polygon, we considered the metrics that show the changes in shrub-lands and patches of bare areas in polygons surrounding each transect.

Any decline in the extent, accumulation and aggregation of shrub-land patches or any growth and spread of bare areas served to quantify disturbance in sampling sites.

Hierarchical Cluster analysis was conducted using Ward's Method in SAS statistical program to discern analogous transects from the point of view of disturbance. Landscape quantitative metrics were considered as clustering variables.

In selecting an appropriate Index of biological integrity, we investigated a group of organisms that had competitive interactions and habitat requirements in common. Recognizing the ecological state of such species specifically their habitat condition, we may have an analysis on the quality of the whole biological system. Since changes in shrub-lands were the main measure of disturbance gradient, we looked for the most dependent species on this area. Referring to Croonquist and Brooks (1991), bird guilds can be an effective indicators demonstrating habitat disturbance. Regarding the possibility of error in real estimation of birds' population in an area (Gibbs and Wenny, 1993), it was necessary to expand the study scale and select the birds that belong to the higher level of organization (Brooks et al., 1998), assuming to be functional and focal in the study area. Considering biological variables of the study area demonstrated, we used abundance of bird guilds in developing the quantitative index of integrity. So birds' comprising guilds were assigned to the three structural, functional and compositional categories based on resource review. (Dayyani, 1996; DOE, 2002 and O'Connell, 2000). Table 3 shows the guilds and the metrics in sub-classes of the main three guild categories that were used to develop the index of integrity. Increasing the number of variables in developing of the Index, improves the degree of differentiation of various attributes. So, tolerant and intolerant guilds as well as shanon-winer index were added to the variables. Tolerant guilds of birds are the ones that their relative abundance did not change by increasing trend of disturbance, but intolerant guilds decreased by disturbance increase.

We sampled transects twice the year, once in spring 2011(mid-April) and the next in summer 2011 (mid-July) when vegetation cover in Miankaleh is at its phonologically optimal condition for the resident birds of the region. The same eight transects that were already considered for determining the disturbance gradient were purposely used to count the bird guilds. Multi-count method was used to measure bird abundance through each transect and within a 50-m radius around it. Any bird species and their abundance were recorded based on the number of heard and seen ones along each transect. The sampling began early in the morning and took until 9am.

Karr and Chu's method (1999) was used but we utilized the relative abundance of bird guilds instead of individual species to quantify the index of integrity. Changing trends of all selected variables in each sampling transects were depicted through the gradient of disturbance in scatter plots. Ascending or descending trend of each bird guild through the gradient of disturbance in scatter plot visually showed their sensitivity to disturbance. Sensitive variables to disturbance gradients were applied to develop the index of integrity. 
Table 3. Potential metrics in developing index of integrity

\begin{tabular}{|c|c|}
\hline $\begin{array}{c}\text { Main Classes } \\
\text { of Bird Guilds }\end{array}$ & Sub-classes of Bird Guilds \\
\hline \multirow{3}{*}{ Function } & Carnivore \\
& Insectivore \\
& Herbivore \\
& Omnivore \\
\hline \multirow{3}{*}{ Structure } & Forest \\
& Grassland \\
& Open land \\
& Wetland and Surrounding \\
& Canopy nester \\
& Open Ground nester \\
& shrub nester \\
\hline Composition & Resident \\
& Migrant \\
& Tolerant Guilds \\
& Intolerant Guilds \\
\hline
\end{tabular}

Selecting the sensitive metrics, we divided the recorded range of each metric to three levels (Diffendorfer et al., 2007 and Karr and Chu, 1999). Score of 1, 3 or 5 assigned to each level using conventional method that Barbour (2000), Diffendorfer et al. (2007), and Karr and Chu (1999) had used in their studies. These triple thresholds were achieved by statistical trisection of the range of values in observed metrics. Then the scores of each metric in all sampling transects were investigated. Score one showed the highest range of degradation and then scores three and five represented the lower and the lowest level, respectively.

The last step in developing the index of integrity is to sum a collection of metrics to a single value in a way that gauges the integrity of the whole ecosystem. Simple sum of different metrics was used as the easiest and most transparent way to estimate the IBI metric.

Accuracy and precision of the developed index were evaluated using various statistical hypotheses. Mean Comparison, cluster analysis, Pearson rank correlation as well as paired sample t-test was applied to evaluate the performance of the index statistically.

Cluster analysis; ward's methodology in SAS statistical program was used to recognize different groups of sampling transects based on value of different integrity metrics in them. It was important to know which transects were categorized in different groups of integrity.

One-Way ANOVA in SPSS 16 was applied to compare means of estimated Integrity Index in various clusters of integrity. For assessing the stability of IBI a paired Sample 
t-test was conducted to assess stability of IBI in the two sampling efforts, using means of IBI in clusters.

Pearson correlation method was used to assess correlation of IBI to the different landscape metrics that were applied to define disturbance gradient in the study area.

\section{Results}

Investigating FRAGSTAT output table, the changes in landscape metrics around each transect were evaluated. Table 4 demonstrates the results of the change happened in amount of each landscape metric for forest patches and patches of bare areas inside each depicted polygon. The result from the cluster analysis using Ward's method with R-Square $=0.98$ suggested that sampling transects can be placed in three distinctive clusters based on level of disturbance. According to the result of clustering, the area that changed from dense shrub-lands to bare area was recognized as high disturbed areas. In contrast, the area that showed the same density of shrub-lands were considered as natural areas and the condition between these two state were regarded as the area of medium level of disturbance. Three of eight transects; transects 1, 2, and 3; were located in intact condition. It named as disturbance level 1 , that showed the lowest level of disturbance .Three of transects; transects 4,5 and 6 were in medium disturbed condition called level 2 and two of them; 7 and 8 were in areas with high level of disturbance that named disturbance level 3. In fact, landscape metrics were applied to confirm this disturbance gradient quantitatively.

Table 4. Change analysis of FRAGSTAT metrics

\begin{tabular}{|c|c|c|c|c|c|c|c|c|c|c|c|c|c|c|}
\hline & Quantit & je cha & of la & scape & etrics & two & fferent & and-ce & er map & of $1985 \mathrm{a}$ & 2010 & & & \\
\hline 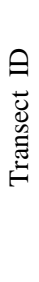 & 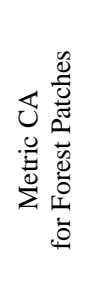 & 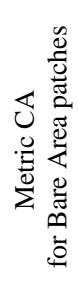 & 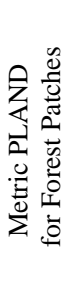 & 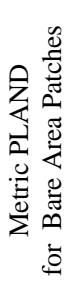 & 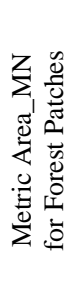 & 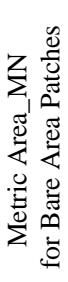 & 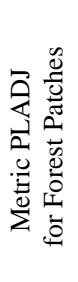 & 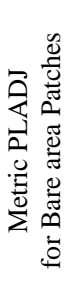 & 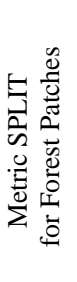 & 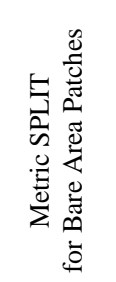 & 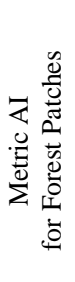 & 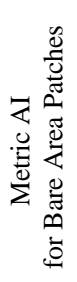 & 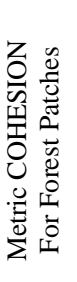 & 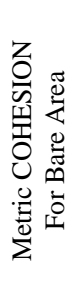 \\
\hline 1 & -78.66 & 46.17 & -3.94 & -2.3 & -129.1 & 2.26 & 1.33 & 1.65 & 0.89 & -72.62 & 1.4 & 1.87 & 0.22 & 0.68 \\
\hline 2 & -170.37 & 74.07 & -8.46 & 3.68 & -75.96 & 2.86 & -2.71 & 8.8 & 40.92 & -4992.54 & -2.47 & 8.04 & -0.5 & 6.87 \\
\hline 3 & -280.44 & 6.03 & -14.1 & -0.3 & -58.75 & -1 & -4.17 & 4.8 & 5.05 & -7184.95 & -3.96 & -4.87 & -0.04 & -5.17 \\
\hline 4 & -420.84 & 282.78 & -21.1 & 14.14 & -40 & 4.88 & -9.8 & 21.9 & 797.4 & -82946.07 & -8.72 & 19.38 & -3.32 & 27.23 \\
\hline 5 & -373.41 & 317.7 & -14.5 & 15.77 & -22 & 4.43 & -6.81 & 20.4 & 1860 & -129624.65 & -4.65 & 16.9 & -4.89 & 22.11 \\
\hline 6 & -454.59 & 233.37 & -22.9 & 11.74 & -58 & 6.8 & -9.87 & 23.9 & 504.7 & -100407.88 & -9.15 & 21.4 & -4.63 & 24.37 \\
\hline 7 & -414.72 & 343.26 & -20.8 & 17.17 & -46.09 & 6.31 & -8.87 & 30.2 & 2608 & -331384.91 & -6.27 & 26.06 & -4.2 & 30.87 \\
\hline 8 & -471.69 & 340.02 & -23.4 & 16.88 & -46 & 5.38 & -9.58 & 29.1 & 2909 & -295253.58 & -6.94 & 25.32 & -3.73 & 31.71 \\
\hline
\end{tabular}

Table 5 shows the summary of the results derived from field measurement. Detail of the field measurement is enclosed in an excel spreadsheet. 
Table 5. Summary of the results of the field Measurements in April and July 2011

\begin{tabular}{|c|c|c|c|c|c|c|c|c|c|c|c|c|c|c|c|c|c|c|c|}
\hline \multirow[b]{3}{*}{$\stackrel{\tilde{\Xi}}{\tilde{\Xi}}$} & \multirow{3}{*}{ 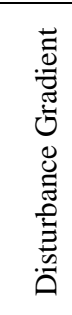 } & \multirow{3}{*}{ 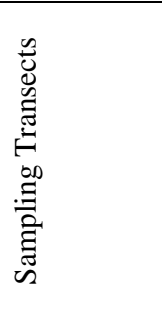 } & \multicolumn{13}{|c|}{ Relative abundance } & \multirow[b]{3}{*}{ 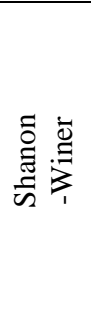 } & \multirow{3}{*}{ 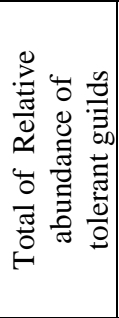 } & \multirow{3}{*}{ 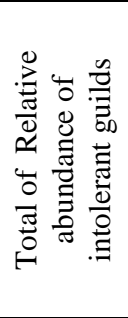 } & \multirow{3}{*}{ 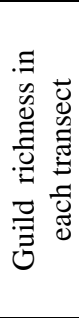 } \\
\hline & & & \multicolumn{4}{|c|}{ Function } & \multicolumn{7}{|c|}{ structure } & \multicolumn{2}{|c|}{ composition } & & & & \\
\hline & & & 苛 & 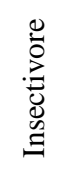 & 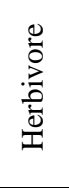 & 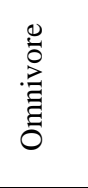 & 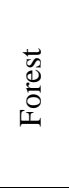 & 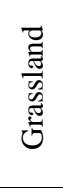 & 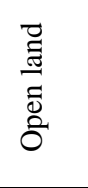 & 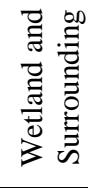 & 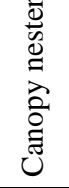 & 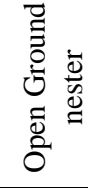 & 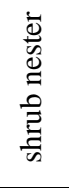 & 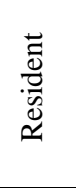 & 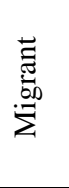 & & & & \\
\hline \multirow{7}{*}{ 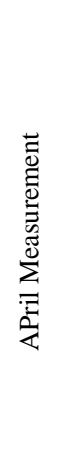 } & \multirow{3}{*}{ 茎 } & Transect 1 & 0.03 & 0.37 & 0.51 & 0.084 & 0.72 & 0.19 & 0.084 & 0 & 0.61 & 0.14 & 0.25 & 0.86 & 0.14 & 4.35 & 1.528 & 2.46 & 12 \\
\hline & & Transect 2 & 0.02 & 0.52 & 0.44 & 0.02 & 0.67 & 0.26 & 0.04 & 0.03 & 0.52 & 0.18 & 0.31 & 0.78 & 0.22 & 4.26 & 1.55 & 2.46 & 13 \\
\hline & & Transect 3 & 0.06 & 0.34 & 0.6 & 0 & 0.86 & 0.12 & 0 & 0.02 & 0.55 & 0.12 & 0.33 & 0.92 & 0.08 & 4.13 & 1.32 & 2.68 & 11 \\
\hline & \multirow{3}{*}{ 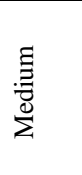 } & Transect 4 & 0.07 & 0.42 & 0.27 & 0.24 & 0.29 & 0.18 & 0.32 & 0.21 & 0.37 & 0.42 & 0.21 & 0.83 & 0.17 & 4.01 & 2.44 & 1.56 & 13 \\
\hline & & Transect 5 & 0.09 & 0.6 & 0.31 & 0.32 & 0.37 & 0.36 & 0.58 & 0.04 & 0.62 & 0.61 & 0.12 & 1.06 & 0.29 & 4.04 & 3.35 & 2.02 & 13 \\
\hline & & Transect 6 & 0.069 & 0.35 & 0.24 & 0.34 & 0.26 & 0.31 & 0.37 & 0.05 & 0.47 & 0.26 & 0.27 & 0.68 & 0.32 & 3.99 & 2.399 & 1.59 & 13 \\
\hline & 离 & Transect 7 & 0.09 & 0.24 & 0 & 0.67 & 0 & 0.08 & 0.78 & 0.14 & 0.03 & 0.97 & 0 & 0.95 & 0.05 & 3.13 & 3.73 & 0.27 & 10 \\
\hline \multirow{8}{*}{ 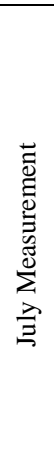 } & \multirow{3}{*}{ 艿 } & Transect 1 & 0.03 & 0.25 & 0.59 & 0.13 & 0.75 & 0.12 & 0.12 & 0.014 & 0.67 & 0.12 & 0.21 & 0.91 & 0.09 & 4.16 & 1.54 & 2.46 & 13 \\
\hline & & Transect 2 & 0.02 & 0.48 & 0.46 & 0.04 & 0.67 & 0.24 & 0.07 & 0.02 & 0.55 & 0.16 & 0.29 & 0.8 & 0.2 & 4.26 & 1.56 & 2.44 & 13 \\
\hline & & Transect 3 & 0.02 & 0.33 & 0.63 & 0.02 & 0.88 & 0.1 & 0.02 & 0 & 0.62 & 0.1 & 0.28 & 0.91 & 0.09 & 4.08 & 1.26 & 2.74 & 12 \\
\hline & \multirow{3}{*}{$\stackrel{\Xi \Xi \Xi}{\Xi}$} & Transect 4 & 0.1 & 0.33 & 0.24 & 0.33 & 0.26 & 0.15 & 0.34 & 0.25 & 0.32 & 0.44 & 0.24 & 0.81 & 0.19 & 3.72 & 2.62 & 1.38 & 13 \\
\hline & & Transect 5 & 0.08 & 0.38 & 0.27 & 0.26 & 0.31 & 0.21 & 0.44 & 0.04 & 0.51 & 0.37 & 0.12 & 0.85 & 0.15 & 3.94 & 2.41 & 1.59 & 13 \\
\hline & & Transect 6 & 0.05 & 0.44 & 0.21 & 0.3 & 0.22 & 0.35 & 0.35 & 0.08 & 0.44 & 0.27 & 0.29 & 0.65 & 0.35 & 4.02 & 2.4 & 1.6 & 13 \\
\hline & \multirow{2}{*}{ 总 } & Transect 7 & 0.12 & 0.25 & 0.13 & 0.68 & 0.13 & 0.1 & 0.81 & 0.15 & 0.21 & 0.98 & 0 & 1.11 & 0.08 & 2.71 & 4.04 & 0.73 & 12 \\
\hline & & Transect 8 & 0.2 & 0.15 & 0 & 0.65 & 0 & 0.1 & 0.71 & 0.18 & 0.08 & 0.87 & 0.05 & 0.9 & 0.1 & 3.05 & 3.72 & 0.28 & 11 \\
\hline
\end{tabular}


Responsive metrics of bird guilds to disturbance gradients were selected using their distributions through scatter plots in both sampling efforts. Figure 1 shows two examples of the scatter plots from the two samplings. Sharp responses of the metrics relative to disturbance gradient either positively or negatively show their sensitivity to disturbance. Carnivores, insectivores, herbivores and omnivores as functional guilds, forest guilds, grassland guilds, open land guilds, guilds of wetland and surrounding, canopy nesters, shrub nesters and open ground nester as structural guilds and tolerant guilds, intolerant guilds and Shannon Winer 's Index as compositional guilds were very keen to the gradient of disturbance and so were finalized for the estimation of biotic integrity.

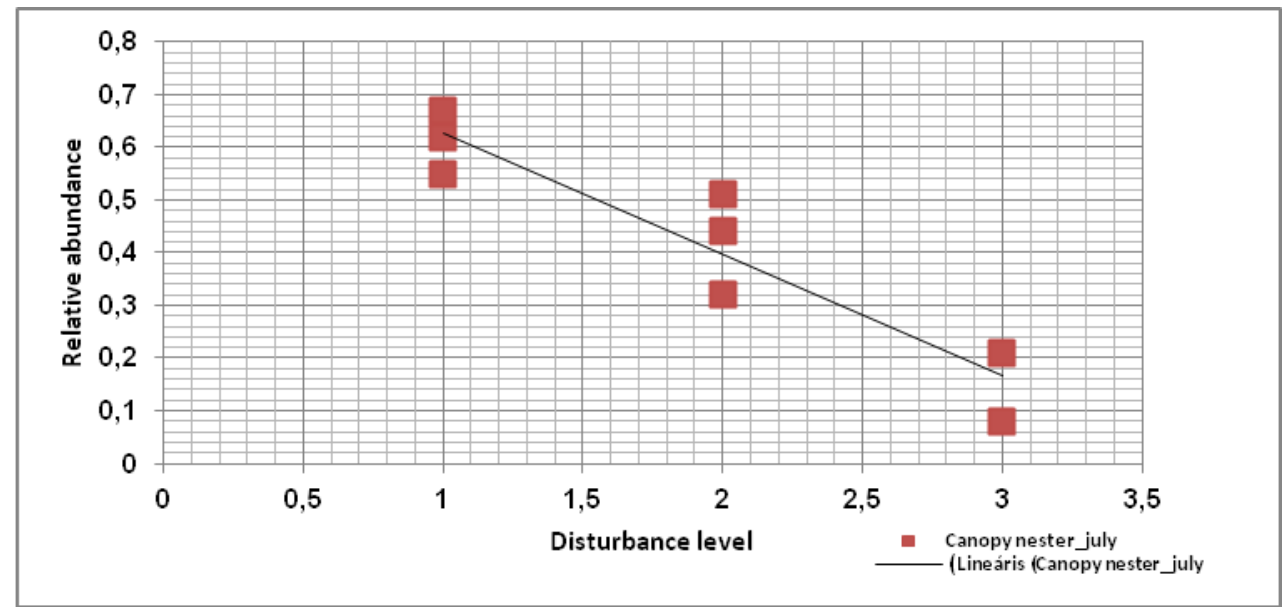

(a)

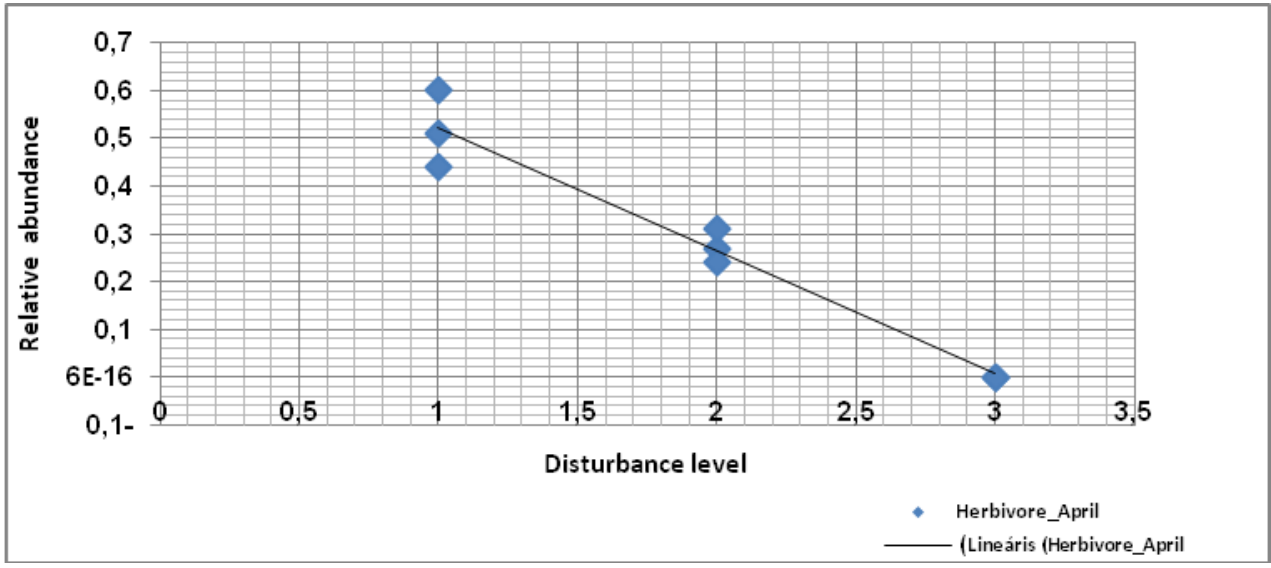

(b)

Figure 1. Scatter plots of potential metrics with linear regressions. (a) Shows how the relative abundance of canopy- nesters change through gradient of disturbance in July sampling.(b) shows the changes of relative abundance of herbivores in April Sampling.

Scoring of each metric through all sampling process, were followed by summing of them in each transect to develop the quantitative index of integrity.

The result of estimated index of integrity in sampling transects was a value between 26 and 68 in a way that value of 26 showed the most degraded transect and value of 68 
showed the transect with lowest amount of disturbance in its integrity. Table 6 shows this result in both sampling times.

Table 6. Results of IBI scores in both sampling times

\begin{tabular}{|ccc|}
\hline $\begin{array}{c}\text { Sampling } \\
\text { Transects }\end{array}$ & $\begin{array}{c}\text { IBI Scores } \\
\text { Spring Sampling }\end{array}$ & $\begin{array}{c}\text { IBI Scores } \\
\text { Summer Sampling }\end{array}$ \\
\hline Transect 1 & 68 & 64 \\
Transect 2 & 64 & 64 \\
Transect 3 & 66 & 66 \\
Transect 4 & 50 & 42 \\
Transect 5 & 46 & 48 \\
Transect 6 & 44 & 44 \\
Transect 7 & 28 & 28 \\
Transect 8 & 30 & 26 \\
\hline
\end{tabular}

Analyses were conducted on the reliability and stability of IBI in calculation of integrity for the Miankaleh Peninsula.

Cluster Analysis: The result of this analysis could show the performance of the developed index in distinguishing the condition of different areas from integrity point of view. Again Ward's method in SAS showed sampling transects can be placed in three distinctive clusters with R-Square $=0.98$ and based on the level of integrity. Results of clustering of the transects in the spring sampling showed that transects 1,2 and 3 formed one cluster, transects 4,5 and 6 made the second cluster and finally transect 7 and 8 created the last cluster. The same grouping appeared in cluster analyses at summer sampling, which contributes to validating the IBI index developed for the study area.

Mean Comparison in different clusters of integrity: The results showed mean of integrity scores in clusters were significantly different in results of the both sampling. For the first sampling, mean of integrity scores was 66 in the first cluster, 46.66 in second cluster and 29 in third cluster with $f=146.63$ and sig $<0.001$. Results of the second measurement showed mean of integrity with 64.66, 44.66 and 27 in clusters 1, 2 and 3 respectively with $f=187.30$ and sig $<0.001$.

Seasonal stability of IBI: Results of Paired Sample t-test showed that a significant correlation existed between integrity values in the two samplings $(r=0.97$ and $\mathrm{P}=<$ .001).The result of a Paired Samples Test is a clear evidence for a non-significant difference $(\mathrm{s}=0.17, \mathrm{t}=1.51)$ among integrity measures in the two samplings. This would be an approval on stability of the index.

Correlation of IBI and disturbance measuring metrics: Table 7 shows the result of Pearson analysis to assess correlation of IBI to the different landscape metrics that were used to assess degree of disturbance around each sampling transects. It shows index of biotic integrity were highly correlated to disturbance measuring metrics. 
Table 7. Correlation of IBI with disturbance measuring metrics

\begin{tabular}{|lll|}
\hline No. & Correlation Factors & R \\
\hline 1 & IBI and metric CA & 0.88 \\
& Forest & \\
2 & IBI and metric PLAND & 0.82 \\
& Forest & \\
3 & IBI and metric & 0.84 \\
& Area_MN Forest & \\
4 & IBI and metric PLADJ & 0.82 \\
& Forest & \\
6 & IBI and COHESION & 0.84 \\
7 & Forest & \\
8 & IBI and SPLIT Forest & -.090 \\
& IBI and AI Forest & 0.85 \\
\hline
\end{tabular}

\section{Discussion}

Three categories of bird guilds (structure, function and composition) were used to build an index of integrity .Quantifying the landscape structure and analyzing the composition and configuration of shrub-lands as the main habitat of the resident birds in Miankaleh, we depicted a gradient of disturbance in biological state of the study area. The analysis on landscape metrics showed that spatial pattern of habitat patches in the study area has changed in a way that large areas of shrub-lands were converted to bare areas or divided in smaller patches of shrub-lands and in contrast, accumulation of bare area increased through the time.

Cluster analyses showed that integrity in different sampling transects could be classified in to three distinctive categories. Results showed biotic integrity in parts of the Miankaleh Peninsula was far from the intact condition. Shrub lands in these areas intensively converted to bare areas. Thus, serious deterioration of natural habitat had happened in these parts.

However, some parts of the Peninsula still exhibit an ecological integrity similar to its natural but not fully intact state. Indices showed that despite of some disturbance forces in such parts, there were a high variety of structural, functional and compositional guilds in them. This confirmed that they could maintain their balance condition. Abundance of intolerant guilds, canopy nesters and herbivore guilds were high in ecologically integrated parts of the Miankaleh. It implied restoration capability in shrub lands has been saved so that they could tolerate grazing forces.

Developed indices of integrity indicated that some parts of Miankaleh are in a condition of moderate integrity. These areas are under threats of degradation in near future. Relative abundance of herbivores and forest dependent guilds in these areas were lower while on the other hand ground nester guilds and dependent guilds to open-land were more abundant in these parts. 
Findings of this research showed division and fragmentation of shrub lands had a strong correlation with developed index of integrity. Fragmentation metrics like PLADJ, COHESION and AI indicated a decline in connectivity of shrub-lands through the time in the belt transects with resultant lowered integrity score. Thus, fragmentation of shrub patches causes a fall in suitability of habitat for dependent bird guilds in the Miankaleh peninsula .So its ecological services especially decreased from habitat point of view.

This study demonstrated that bird guilds can be used in developing an ample index of integrity to quantify the ecological condition of a natural ecosystem. Their relatively inclusive nature allows a comprehensive approach toward measuring integrity. Such an index is more complete and flexible than single species approach. Besides it is technically easier and economically more effective than using different taxa to develop an index of biotic integrity while it covers assessment of many ecological attributes. Correlation of structure and function of the Miankaleh ecosystem were possible using a multi-index of bird guilds that were dependent to the spatial attribute of the Miankaleh landscape. Obviously, no management action would be effective unless a proper understanding of the area's real ecological condition exists. Then such an ecological index can help to assess effects of the disturbance factors on the natural ecosystem of Miankaleh to prioritize the best actions for restoring this ecosystem. Since integrity is a scale dependent subject, a complementary study in higher scale and regional level is suggested to develop a regional index of integrity.

Acknowledgments. Correspondent author specially thanks Department of Environment, school of planning at University of Waterloo for providing the opportunity for conducting this research. I give my special thanks to Tarlan experts for their help in field work of this research.

\section{REFERENCES}

[1] Andersen, A.N. (1995): A classification of Australian ant communities based on functional groups which parallel plant life-forms in relation to stress and disturbance. $-\mathrm{J}$. Biogeogr 22: 15-29.

[2] Andreason, J. K., O’Neill, R.V., Noss, R. and Slosser, N.C. (2001): Considerations forthe development of a terrestrial index of ecological integrity. - Ecol. Indic. 1: 21-35.

[3] Angermeier, P.L. and DavideanuG. (2004): Using fish communities to assess streams in Romania: initial development of an index of biotic integrity. - Hydrobiologia 511: 65-78.

[4] Barbour, M.T., Swietlik, W.F., Jackson, S.K., Courtemanch, D.L., Davies, S.P. and Yoder, C.O. (2000): Measuring the attainment of biological integrity in the USA: a critical element of ecological integrity. - Hydrobiologia 453-464.

[5] Bedoya, D., Novotnya, V. Manolakos, E.S. (2009): In-stream and off-stream environmental conditions and stream biotic integrity importance of scale and site similarities for learning and prediction. - Ecol. Modell. 220:2393-2406.

[6] Borges, P.A.V., Serrano, A.R. and Quartau, J.A. (2000): Ranking the Azorean natural forest reserves for conservation using their endemic arthropods. - J. Insect. Conserv. 4:129-147.

[7] Borja, A., Ranasinghe, A. and Weisberg, S.B. (2009): Assessing ecological integrity in marine waters, using multiple indices and ecosystem components: Challenges for the future. - Mar. Pollut. Bull. 59: 1-4.

[8] Bradford, D.F., Franson, S.E., Neale, A.C., Heggem, D.T., Miller, G.R. and Canterbury, G.E. (1998): Bird species assemblages as indicators of biological integrity in Great Basin rangeland. - Environ. Monit. Assess. 49: 1-2. 
[9] Blair, R.B. (1996): Land use and avian species diversity along an urban gradient. - Ecol. Appl. 6: 506-519.

[10] Brooks, R.P., O’Connell, T.J., Wardrop, D.H. and Jackson, L.E. (1998): Towards a regional index of biological integrity: the example of forested riparian ecosystems. Environ. Monit. Assess. 51: 131-143.

[11] Browder, S.F., Johnson, D.H. and Ball, I.J. (2002): Assemblages of breeding birds as indicators of grassland condition. - Ecol. Indic. 2:257-270.

[12] Cardoso, P., Borges, P.A.V. and Gaspar, C. (2007): Biotic integrity of the arthropod communities in the natural forests of Azores. - Biodivers. Conserv. 16: 2883-2901.

[13] Carignan, V. and Villard, M.A. (2001): Selecting indicators to monitor ecological integrity: A review. - Environ. Monit. Assess. 78:45-61.

[14] Croonquist, M.J. and Brooks, R.P. (1991): Use of avian and mammalian guilds as indicators of cumulative impacts in riparian wetland areas. - Environ. Manage. 15:701714.

[15] Cairns, J.R. and Van der Shali, W.H. (1980): Biological monitoring: Part I- early warning systems. - Water Res. 14:1179-1190.

[16] Cody, M.L. (1981): Habitat selection in birds: the roles of vegetation structure, competitors, and productivity. - Bioscience 31:107-113.

[17] Dayyani, A.A. (1996): Birds of Middle and Near East. - University of Tehran publication, Tehran

[18] Dearborn, D.C., Anders, A.D. and Flint, E.N. (2001): Trends in reproductive success of Hawaiian seabirds: is guild membership a good criterion for choosing indicator species? Biol. Conserv. 101: 97-103.

[19] Diffendorfer, J.E., Fleming, G.M., Duggan, J.M., Chapman, R.E., Rahn, M.E., Mitrovich, M.J. and Fisher, R.N. (2007): Developing terrestrial, multi-taxon indices of biological integrity: An example from coastal sage scrub. - Biol. Conserv. 140:130-141.

[20] Donovan, T.M., Thompson, F.R., Faaborg, J. and Probst, J.R. (1995): Reproductive success of migratory birds in habitat sources and sinks. - Conserv. Biol. 9: 1380 -1395.

[21] Dyer, M.I. and Holland, M.M. (1991): The Biosphere reserve concept: needs for a network design. - Bioscience 4:319-325.

[22] Franklin, J.F. (1993): Preserving biodiversity: species, ecosystems, or landscapes? - Ecol. Appl. 3:202-205.

[23] Freemark, K. and Collins, B. (1992): Landscape ecology of birds breeding in temperate forest fragments. - In: Hagan, J.M. and Johnston, D.W. (ed.) Ecology and Conservation of Neo-tropical Migrant Land birds. (pp.443-454). Smithsonian Institution Press, Washington

[24] Gibbs, J.P. and Wenny, D.G. (1993): Song output as a population estimator: Effect of male pairing status. - J. Field Ornithol. 64:316-322.

[25] Glennon, M.J. and Porter, W.F. (2005): Effects of land use management on biotic integrity: An investigation of bird communities. - Biol. Conserv. 126: 499-511.

[26] Gosselink, J.J. (1990): Landscape conservation in a forested wetland. - Bio-Science 40:588-600.

[27] Hobbs, R.J. (1994): Fragmentation in the wheat belt of Western Australia: landscape scale problems and solutions. - In: Dover, J. (ed.) Fragmentation in agricultural landscapes. International association of landscape ecology. (pp.3-20), United Kingdom: Garstang.

[28] Hoffmann, B.D. and Anderson, A.N. (2003): Responses of ants to disturbance in Australia, with particular reference to functional groups. - Austral. Ecology 28:444-464.

[29] Iran Department of Environment, Unpublished. Management plan of Miankaleh wildlife refuge. Ravanab Consultant.

[30] Iran Department of Environment, Unpublished. Comprehensive management plan of Miankale wildlife refuge and biosphere reservoirs. Royan Consultant.

[31] Iran Department of Environment, (1988): Land use Map of Miankaleh peninsula. 
[32] http://www.umass.edu/landeco/research/fragstats/fragstats.html,2010.

[33] Karr, J.R. and Dudley, D.R. (1981): Ecological perspective on water quality goals. Environ. Manage. 5: 55-68.

[34] Karr, J.R. (1981): Assessment of biotic integrity using fish communities. -Environ. Manage. 6:21-27.

[35] Karr, J.R. and Chu, E. (1999): Restoring life in running waters: Better biological monitoring. - Island Press, Washington, DC.

[36] Kimberling, D.N., Karr, J.R. and Fore, L.S. (2001): Responses of terrestrial invertebrates to human disturbance in shrub-steppe in eastern Washington. -Ecol. Indic. 1: 63-81.

[37] Lambeck, R.J., (1997): Focal species: a multi-species umbrella for nature conservation. Conserv. Biol. 11:849-856.

[38] Majer, J.D. and Beeston, G., (1996): The biodiversity integrity index: an illustration using ants in Western Australia. - Conserv. Biol. 10: 65-73.

[39] Miller, S.J., Wardrop, D.H., Mahaney, W.M. and Brooks, R.P. (2006): A plant-based index of biological integrity (IBI) for headwater wetlands in central Pennsylvania. - Ecol. Indic. 6: 290-312.

[40] Muller, F. (2005): Ecosystem indicators for the integrated management of landscape health and integrity. - In: Jorgensen, S.E. Costanza, R. and Xu, F. L. (ed.) Handbook of ecological indicators for assessment of ecosystem health, Taylor and Francis, CRC Press, Boca Raton, FL.

[41] Noss, R.F. (1983): A regional landscape approach to maintain biodiversity. -Bioscience 33:700-706.

[42] Noss, R.F. (1987): From planet communities to landscape in conservation inventories: a look at the nature conservancy (USA). - Biol. Conserv. 41:11-37.

[43] O'Connell, T.J., Jackson, L.E. and Brooks, R.P. (2000): Bird guilds as indicators of ecological condition in the central Appalachians. - Ecol. Appl. 10: 1706-1721.

[44] Rapport, D.J. (1990): Challenges in the detection and diagnosis of pathological change in aquatic ecosystems. - J. Great Lakes Res. 16:609-618.

[45] Rothrock, P.E., Simon, T.P., Stewart, P.M. and Rowland, J. (2003): A new approach to selecting sustainable ecosystem indicators: A neural network. Ph.D. Thesis. Royal Military College of Canada.

[46] Solimini, A.G., Cardoso, A.C.,Carstensen, J.,Free,G.,Heiskanen, A.S.,Jepsen,N.,Noges,P.,Poikane,S. and Van de Bund,W. (2008): The monitoring of ecological status of European freshwaters. - In: Quevauviller, P. Borchers, U. Thompson, C. and Simonart, T. (ed.), The Water Framework Directive: Ecological and Chemical Status Monitoring (pp. 29-60), Wiley, Chippenham, Wiltshire

[47] Taft, J.B., Hauser, C. and Robertson, K.R. (2006): Estimating floristic integrity in tallgrass prairie. - Biol.Conserv. 131:42-51.

[48] Walker, B. (1995): Conserving biological diversity through ecosystem resilience. Conserv. Biol. 9: 747-752.

[49] Woodley, S. Kay, J. and Francis, G. (1993): Ecological integrity and the management of ecosystems. - St. Lucie Press, Florida

\section{APPENDIX}

Electronic Appendix: Field Data 